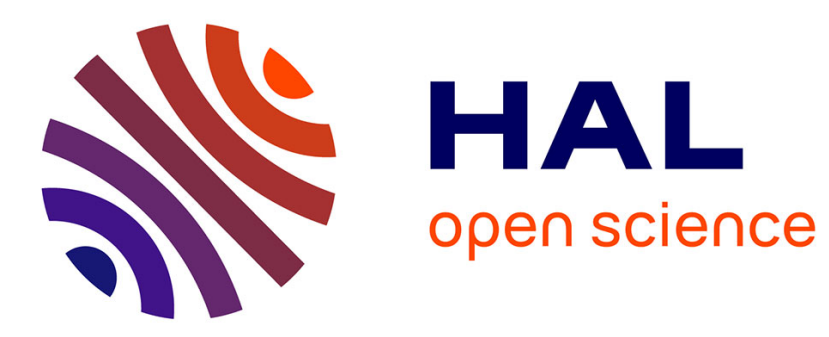

\title{
Designing an efficient humanitarian supply network
}

Aurelie Charles, Matthieu Lauras, Luk N. van Wassenhove, Lionel Dupont

\section{To cite this version:}

Aurelie Charles, Matthieu Lauras, Luk N. van Wassenhove, Lionel Dupont. Designing an efficient humanitarian supply network. Journal of Operations Management, 2016, 47-48 (1), pp.58-70. 10.1016/j.jom.2016.05.012 . hal-01532132

\section{HAL Id: hal-01532132 \\ https://hal.science/hal-01532132}

Submitted on 9 Jun 2017

HAL is a multi-disciplinary open access archive for the deposit and dissemination of scientific research documents, whether they are published or not. The documents may come from teaching and research institutions in France or abroad, or from public or private research centers.
L'archive ouverte pluridisciplinaire HAL, est destinée au dépôt et à la diffusion de documents scientifiques de niveau recherche, publiés ou non, émanant des établissements d'enseignement et de recherche français ou étrangers, des laboratoires publics ou privés. 


\title{
Designing an efficient humanitarian supply network
}

\author{
Aurelie Charles* $^{*}$, Matthieu Lauras ${ }^{\mathrm{b}}$, Luk N. Van Wassenhove ${ }^{\mathrm{c}}$, Lionel Dupont ${ }^{\mathrm{d}}$ \\ ${ }^{a}$ Université de Lyon, DISP laboratory, 160 bd de l'université, 69500 Bron,France (e-mail: a.charles@univ- \\ lyon2.fr tel: +33664525806$)$ \\ * Corresponding author \\ ${ }^{\mathrm{b}}$ Université de Toulouse -Mines Albi, Route de Teillet, 81013 Albi, France (e-mail: lauras@mines-albi.fr) \\ ${ }^{\mathrm{c}}$ INSEAD, Bld de Constance, 77300 Fontainebleau, France (e-mail: luk.van-wassenhove@insead.edu) \\ ${ }^{\mathrm{d}}$ Universite Toulouse -Mines Albi, Route de Teillet, 81013 Albi, France (e-mail:dupont@mines-albi.fr)
}

\begin{abstract}
Increasingly, humanitarian organizations have opened regional warehouses and pre-positioned resources locally. Choosing appropriate locations is not easy and frequently based on opportunities rather than rational decisions. Dedicated decision-support systems could help humanitarian practitioners design their supply networks. Academic literature suggests the use of commercial sector models but rarely considers the constraints and specific context of humanitarian operations, such as obtaining accurate data, high uncertainties, limited budgets and increasing pressure on cost efficiency. We propose a tooled methodology to properly support humanitarian decision makers in the design of their supply chains. Our contribution is based on the definition of aggregate scenarios to reliably forecast demand using past disaster data and future trends. Demand for relief items based on these scenarios is then fed to a mixed-integer linear programming model in order to improve current supply networks. The specifications of this model have been defined in close collaboration with humanitarian workers. The model allows analysis of the impact of alternative sourcing strategies and service level requirements on operational efficiency. It provides clear and actionable recommendations for a given context, bridging the gap between academics and humanitarian logisticians. The methodology was developed to be useful to a broad range of humanitarian organizations, and a specific application to the supply chain design of the International Federation of Red Cross and Red Crescent Societies is discussed in detail.
\end{abstract}

Keywords:

Supply Chain, Network Design, Facility Location, Humanitarian Aid, Pre-positioning, Demand, Uncertainty, Efficiency 


\section{Introduction}

Humanitarian organizations (HOs) need to respond quickly to crises, providing medical aid, shelter, food, and water to victims. Disaster relief largely depends on logistics, so improvements in this area have major impacts on the three performance dimensions of relief operations: effectiveness (quality), responsiveness (time), and efficiency (cost). In order to improve their operations, organizations "have to work hard not only during disasters but also between disasters" (Van Wassenhove 2006). Consequently, most organizations have recently reexamined their logistics networks or are considering doing so.

Research on supply networks is well-established and discusses both centralized and decentralized systems. Centralized systems enable risk pooling and are generally better in terms of safety stocks, overhead costs, and economies of scale (Simchi-Levi et al. 2003). Decentralized systems have better lead times and therefore seem to fit well with the humanitarian need for quick response. A swift response is vital for victims but also essential for favorable media coverage which has a strong impact on funding. Advanced and decentralized stockpiling of a variety of resources is crucial for a fast, adequate, and efficient response, given the cost of intercontinental airlifts.

Most HOs have transited to decentralized supply networks, capitalizing on improved delivery service by getting closer to the field (Gatignon et al. 2010). The Pan American Health Organization (PAHO) lists short delivery times, reduced transportation costs, and building local capacity as the major advantages of a decentralized system. It also points out that local shipments normally require less documentation than international consignments. In addition, a decentralized system increases the quality and predictability of local purchases and supports the local economy (PAHO 2001). According to the International Federation of Red Cross and 
Red Crescent Societies (IFRC), decentralized networks also increase visibility and coordination with national societies and other local nongovernmental organizations (NGO). However, HOs have historically behaved rather opportunistically in reconfiguring their logistics networks. They have built their stocks where they already had operations or have identified convenient locations based on proximity to an airport or special customs and tax advantages in some countries. By failing to systematically consider all options, they may have missed out on better locations.

Designing an optimal supply network is a major challenge for humanitarian practitioners. The trend toward more frequent medium-sized disasters imposes a simultaneous management of multiple relief operations around the world. A performing supply network is therefore crucial to HOs. In addition, donors are pledging millions in an economic context that demands rationalization. They seek more accountability and cost efficiency and are less tolerant to the old fire-fighting mentality that characterized many relief operations.

The IFRC recognized these issues as early as 2007, during a meeting at its Geneva headquarters, shortly after the reorganization of its logistics network. The organization faced critical questions: "What stock should we hold? How much, and where?" (IFRC 2007). They needed answers to these questions, and they also wanted to know which parameters impact the decision process. Despite clear improvements with their decentralized supply network, these questions remain relevant today.

Recent academic publications on facility location have applied commercial approaches to the context of disaster relief (see section 2 for details). Our review shows that this strategy has reached its limits. First, the research frequently uses fictitious scenarios and data to compensate for the lack of realistic information. This approach is no longer sufficient to validate whether decision support systems can be successfully applied in the actual context of disaster relief. Real cases with accurate data are necessary to enable HOs to start using the 
results of academic studies. Our first research objective is to carefully generate realistic data based on past and future disaster trends, as suggested by Galindo and Batta (2013) and Pedraza-Martinez and Van Wassenhove (2013). Second, research (see section 2 for details) has focused on effectiveness (quality) and responsiveness (time) of humanitarian networks. We asked HOs about their real concerns regarding network design, using semi-structured interviews, and consistently got the same response. Starting the interview with an open question, effectiveness is indeed mentioned as the key objective. But after discussion, once we explained the difference between "what is the most important" and "what is the right objective function", interviewees agreed that effectiveness (quality) and responsiveness (time) are a target to be met for the organization, e.g. reaching $\mathrm{x}$ beneficiaries with $\mathrm{y}$ essential relief items within $\mathrm{z}$ days. However, the real concern of HOs in building their supply networks is how to achieve this target, and how to do so in the most cost efficient way.

It may help to understand this better when one considers the fact that HOs have a limited budget to respond to disasters. Cost efficiency simply allows these organizations to reach more beneficiaries. Consequently, we develop a model that reflects these priorities, i.e. in which cost efficiency is the objective and quality (effectiveness) and timeliness are constraints. In sum, our research follows the recommendations of Schmenner et al. (2009): "focus on what appears to be important to know, what we understand about it, and what we can do to understand it better". Facility location problems have received much attention, so the main goal was not to propose a fundamentally novel method but a dedicated model capable of ensuring that HOs find relevant answers to their problems. The study provides answers regarding the optimal configuration (one-stage or two-stage network), the optimal number, size and location of warehouses and the impact of alternative sourcing strategies on decisions. 


\section{Literature review and research statements}

\subsection{Gap between needs and research in the humanitarian sector}

The number of scientific and managerial publications on humanitarian logistics has increased considerably in recent years. Yet few, if any, HOs actually use optimization-based decisionsupport systems. Authors such as Galindo and Batta (2013) and Van Wassenhove and Pedraza-Martinez (2012) have argued that, to bridge this gap, research should be more realistic and consider real-world problems and data on past, present, and future disaster trends. However, researchers find it difficult to obtain accurate and, above all, reliable data (Van Wassenhove 2006; Peres and Brito 2012).

More research should be done in close collaboration with HOs. Academics need to learn about the challenges and priorities of this specific sector. We have interviewed a dozen logistics decision makers from various HOs (IFRC, Médecins Sans Frontières (MSF), World Vision International (WVI), Word Food Program (WFP)). Objectives, constraints, availability and accuracy of data were discussed. Interviewees notably insisted that their problem is not maximizing coverage because (i) plane deliveries allow them to quickly cover large distances, and (ii) search-and-rescue activities and needs assessment are the priorities in the first hours after disasters. HOs need to ensure that relief items reach affected areas at the most appropriate times to correctly prioritize actions in the field, and to avoid bottlenecks and needless competition for scarce transportation resources.

To formulate models that use realistic assumptions and produce more applicable research, Galindo and Batta (2013) argue that it is necessary to conduct a formal analysis with a solid statistical basis. Research in the humanitarian sector will be applied by HOs only if they trust the findings. Altay and Green (2006), Simpson and Hancock (2009), Lettieri et al. (2009), and Galindo and Batta (2013) recently conducted reviews of disaster management literature and identified its strengths and weaknesses. They propose clear directions to increase the 
relevance and impact of research on HOs. In particular, they suggest: (i) building realistic assumptions and scenarios, (ii) improving the efficiency capabilities of humanitarian networks and (iii) considering the effect of data uncertainty on the results. Our approach is aligned with these recommendations.

\subsection{Facility location problems in disaster relief}

\subsubsection{Choice of the objective function: effectiveness, responsiveness, or efficiency?}

Facility location models dedicated to the not-for-profit sector mostly focus on the response phase (Barbarosoglu et al. 2002, Ozdamar et al. 2004, Yi and Ozdamar 2007 and Campbell et al. 2008). More than one-third of research papers focus on early response (Galindo and Batta 2013). Another often-studied problem concerns setting up a local, pre-positioning system (Hale and Moberg 2005, Salmeron and Apte 2010, Rawls and Turnquist 2010, and Mete and Zabinsky 2010). Among the facility location articles dedicated to disaster relief, only a small proportion adopt a preparedness perspective and consider the global supply network (Akkihal 2006, Lodree and Taskin 2007, Balcik and Beamon 2008, Ukkusuri and Yushimito 2008, Campbell and Jones 2011, Duran et al. 2011 and Yushimito et al. 2012).

All these papers focus on maximization of effectiveness or responsiveness. Effectiveness is defined as the "ability to deliver the correct product, to the correct place, at the correct time, in the correct condition and packaging, in the correct quantity, with the correct documentation, to the correct user" (Supply Chain Council 2006), while responsiveness is the "ability to evaluate and take needs into account quickly" (Charles et al. 2010). To the best of our knowledge, only one facility location model applied to disaster relief (Tzeng et al. 2007) deals with efficiency, defined as "the most economical way to do an activity" (Lauras et al. 2010). Tzeng et al. (2007) used a multi-objective programming method with three objectives: minimize total cost, minimize total travel time, and maximize minimal satisfaction during the planning period. However, the authors discussed only a single application of this model and 
gave no recommendations for the optimal design of global supply networks. In short, the existing literature on disaster relief privileges effectiveness and responsiveness, in line with the findings of Gralla (2014).

We agree that for humanitarian workers involved in the response phase, facing thousands of people in need of urgent help, maximizing the total cargo sent seems an appropriate objective. Unfortunately, this approach often leads to a chaotic situation in the field, where too few logisticians handle huge amounts of products, without the proper infrastructure in place, creating new or worsening existing bottlenecks. With a more global and detached approach, stressing the preparedness view we advocate, this firefighting mentality can be avoided. This approach presents the advantage of enabling HOs to state what they pledge to do and then to decide who will do what, and this before the event of a disaster. In addition, organizations can be made accountable because it is easier to measure if they did what they promised. The IFRC has clearly taken this approach which could be summarized as "say what you do and do what you say", as have other large international organizations.

\subsubsection{Choice of methodology: Deterministic, robust, or stochastic?}

Stochastic optimization models are frequently used to deal with demand uncertainty. Bertsimas and Thiele (2006) argue that stochastic programming, in which probability distributions represent first-order variables, is a powerful modeling tool when a random probability description is available. However, in the humanitarian context decision makers do not have such information, certainly not for non-cyclical disasters. Therefore, purely stochastic facility location models do not seem immediately applicable.

Robust models could be considered for humanitarian contexts where probability distributions are not readily accessible. Klibi et al. (2010) define robustness as a measure of useful flexibility supported by decisions that leave some allowance for future choices. The authors used this definition to optimize a situation with pre-established scenarios where the solution 
needed to perform well whatever scenario eventually panned out (Baud-Lavigne 2012). Much research in humanitarian operations has used a similar approach. Mete and Zabinsky (2010) focused on medical supplies sent following an earthquake around Seattle. The contribution of this paper is clear, but its applicability is limited to "any other city with the necessary data provided by different stakeholders of previous disaster management." (Mete and Zabinsky 2010). Our research objective is to design a supply network which enables better response to most natural crises occurring all over the globe, not only those affecting specific locations. Rawls and Turnquist (2010) and Salmeron and Apte (2010) also applied robust models to a local level. Again, the specific application is situated in a developed area where enough information to build probabilistic scenarios is available. This approach would only partially apply to a larger developing area, where data are hard to get.

On average, stochastic and robust models optimize the random outcome: "This is justified when the Law of Large Numbers can be invoked and we are interested in the long-term performance, irrespective of the fluctuations of specific outcome realizations" (Shapiro et al. 2009). In our case, these fluctuations have potentially devastating impacts on human lives. If a humanitarian organization's network has flaws in a few specific cases where probability of crisis occurrence is low, then it cannot send assistance to victims in these locations on time. Organizations should know exactly where these gaps are. A deterministic approach with multiple scenarios can provide much clearer information on gaps than a stochastic or robust approach.

Santoso et al. (2005) studied the strengths and weaknesses of deterministic, stochastic, and robust programming approaches for supply chain design and pinpointed two important issues. First, the advantage of a stochastic compared to a deterministic approach in an uncertain environment is not as significant in the case of strategic decisions, such as network design. The macroscopic scale of the analyzed data can explain this. Demand forecasts are generally 
more accurate at an aggregate than a detailed level. Consequently, uncertainties are smaller, and stochastic or robust approaches are not required. Second, existing stochastic and robust programming approaches for supply chain design under uncertainty are suitable for situations with a small number of scenarios. This issue is especially relevant to our study since we must run our model based on a large and fully representative set of scenarios for our conclusions to be as realistic as possible.

Our objective is to develop a research study that practitioners can discuss and validate. HOs generally have little or no experience with optimization approaches. Their confidence in modeling is low, especially if they cannot fully understand the underlying assumptions and mechanisms. Robust and stochastic approaches suffer from this because the probabilities are not easy to establish and justify in practice. Based on all these considerations, we followed the recommendation from Shapiro (2000) to construct multiple scenarios of an uncertain future and optimize a MILP model for each scenario. Such deterministic optimization of a strategic supply chain planning problem appears to be the most practical approach. Estimating key parameters is difficult, especially in our context where data are difficult to gather and decisions are quite macroscopic. For such problems, it is not realistic to attempt to develop and validate extensive descriptions of how parameters might vary in the future. In summary, we chose to use a deterministic approach based on MILP. This enables us to take into account requirements on service levels during a relief operation. These constraints on sending relief items create dependence over time, which is not easy to model with a stochastic or robust approach. In addition, this approach makes it possible to obtain a clear vision of which crises types or geographical areas are well or poorly covered by the chosen logistics network. This clarity regarding the outcomes, model, and inputs also makes it easier to convince HOs to use our research. 


\subsection{Research study}

To determine the best locations for pre-positioning humanitarian resources at a strategic level, we performed both a general blank-page analysis and a dedicated study for the IFRC. Other organizations can use the logic of the MILP scenario analysis and the subsequent interpretation of research outputs and sensitivity analyses. However, they need to carefully adapt their MILP formulation, which might differ from the IFRC model because organizations have different mandates and missions. Therefore, the methodology is generalizable, but its application is specific to each organization. To ensure the empirical grounding of the study, we focused on three main elements. First, we invested a great deal of time and energy in making explicit and consolidating humanitarian experiences. We conducted a huge amount of work with the IFRC to understand and model its problems. Second, we sought to make the methods and models easily adaptable to various organizations. Third, we focused on data collection to ensure that our inputs were as close to reality as possible.

\section{Toward realistic models of data}

Models used in scientific approaches perform two fundamentally different representational functions (Frigg and Hartmann 2012). Models of data represent a selected part of the world (the target system). Models of theory represent a theory or a decision-making support in the sense that the model interprets the laws and axioms of that theory. A model of data is a corrected, rectified, regimented, and often idealized or simplified version of the data gained from observations (raw data) (Frigg and Hartmann 2012). Models of data play a crucial role in validating theories because we compare models of data -not the often messy, inaccessible, and complex raw data- to theoretical predictions. In the humanitarian context, the vital importance of models of data is increased by the major difficulty of collecting, gathering, and 
understanding data. This challenge must be addressed to validate scientific propositions and ensure their validity in a humanitarian context.

In this paper, we propose to avoid this shortcoming of most previous research on humanitarian facility location problems by constructing a realistic model of data. The concept of realism is seen as the will to get as close as possible to how humanitarian practitioners operate, in contrast to what academics hypothesize they do or should do.

We used information from public databases and interviews with practitioners. Transportation costs and times are based on quotes provided by a major transportation company and independently validated by discussions with practitioners from MSF and two private companies. Fixed and variable costs were calculated based on regional average salaries and Gross National Income/Gross Domestic Product (GNI/GDP) for the duration of the operations. This is not a one-time cost for opening the facility but the cost of maintaining a functioning warehouse in a specific region. Information on purchase costs and supplier locations came from the interviews and the IFRC website. Initial values for parameters, such as the required level of service in terms of responsiveness and effectiveness, and the size of the contingency stock, were also derived from discussions with the IFRC.

\subsection{Scenarios of demand}

Scenarios of demand were built into the modelling system after a deep analysis of past disasters. For our study, we used the international disaster database EM-DAT (Guha-Sapir 2015). We limited our analysis to disasters recorded after 2000 to ensure coherence within the database. Indeed, statistical reports from EM-DAT show "a differentiated evolution since 2000" and contend that the increase in the quantity of recorded disasters "can be partially explained by increased reporting of disasters, particularly by press organizations and specialized agencies." (Hoyois et al. 2007). 
The analysis of data from past disasters provides valuable information about disaster trends (e.g., location, intensity, typology, seasonality). The results of Charles (2010) on this issue show a correlation between the type and location of a disaster. Most occurrences also share characteristics, such as seasonality, indicating that disasters are not entirely unpredictable. This analysis of the size, type, and location of past disasters indicates that the global occurrence and intensity of disasters has remained constant over the last decade (Charles, 2010). On the aggregate, demand can be forecast fairly accurately based on past disaster data and future trends (e.g., climate change effects). Of course, a sudden-onset earthquake and the consequent needs cannot be predicted precisely, but on average forecasts are accurate enough when considering where to locate warehouses and pre-position supplies (see Figure 1). Therefore, data from past disasters were chosen to use in the first analysis and as a basis for constructing scenarios. To guarantee the relevance of our conclusions, we also analyzed the sensitivity of the results to potential changes in future demand. An analysis of future trends and their impact on supply network design can be found in section 6 .

Figure 1: Evolution of the location of natural crises over the years.

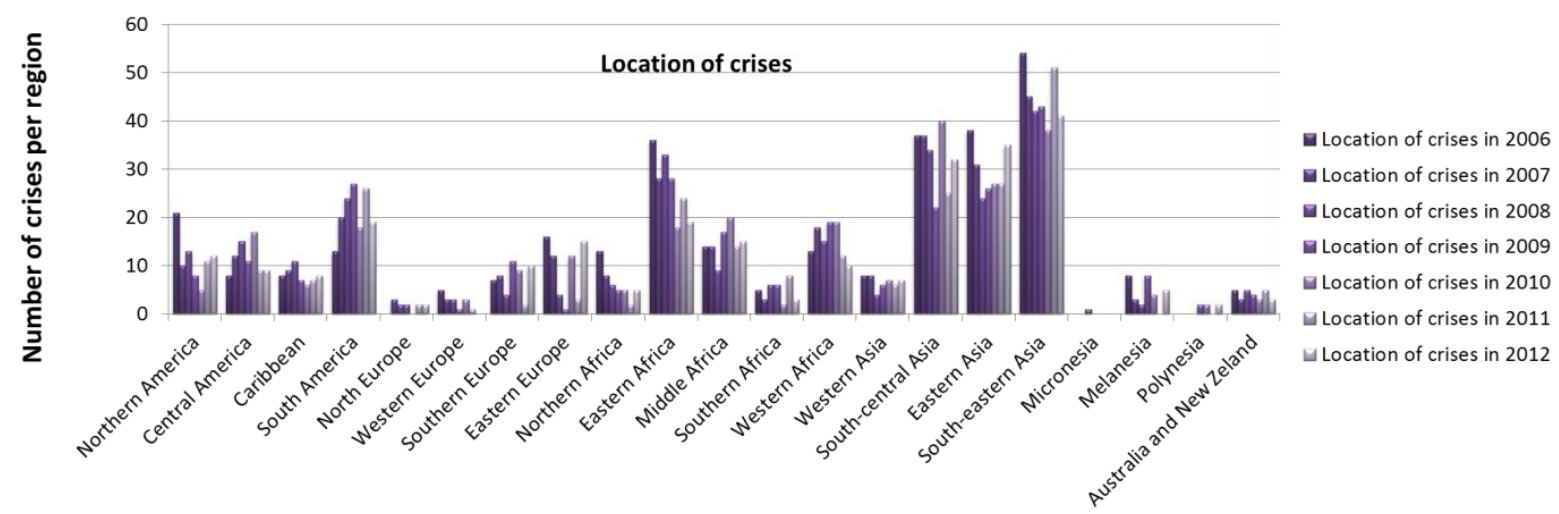

Figure 2 provides information on the location of crises and their impacts by region. The higher vulnerability of Asian regions, for example, is clear from this map. It is also evident that there is no correlation between the number of crises (illustrated by the stars in light grey) and the number of individuals affected (illustrated by the stars in black). For example, there 
are more crises in Eastern Africa than Eastern Asia, yet crises in Eastern Asia affect many more people. Consequently, a model that focuses only on the number of people affected, without taking disaster frequency into account, would completely overlook western Africa and the Caribbean, for example.

Figure 2: Geographical repartition of crises over a three-year period (2006, 2007 and 2008)

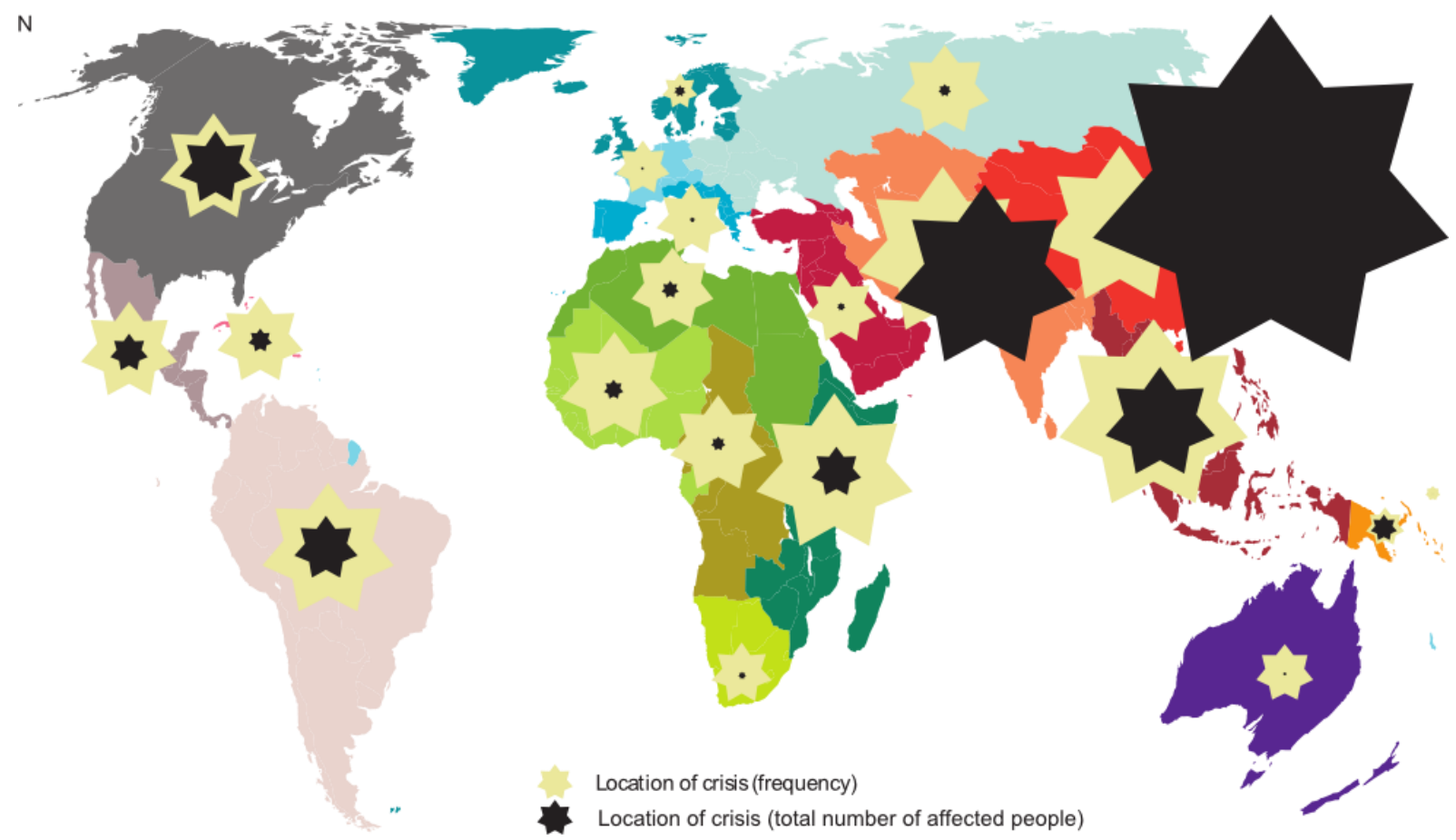

The scenarios used as input for our model were constructed based on a list of 1,000 recent disasters. This list details the disaster type, location, and number of individuals affected in each case. One scenario represents demand in terms of product types and quantities needed to respond to all disasters occurring simultaneously throughout the world. If two crises happen within the same timeframe, then the model aggregates the demands of these crises, even if they are not in the same region. A single scenario might involve anywhere from 1 to 26 simultaneous disaster responses. In total, 173 scenarios were used as input for the model to guarantee a full representative year and a complete analysis of results. Analyses of 557 scenarios covering a period of 3 years were also performed to validate the robustness of the findings. 
As explained in section 2, the objective is not to send all products as quickly as possible. Products have to arrive incrementally and staged over time to avoid creating bottlenecks, putting too much pressure on field logisticians, and to leave space for other critical activities during the first days of disaster response. To take these facts into account, three timeframes were defined for the optimization, with a specific number of beneficiaries set as the target for each timeframe. For example, the IFRC's specifications hold that, for a disaster affecting a population of 200,000 people, the supply network should be able to provide assistance to 5,000 families of 5 within 5 days, 15,000 families within 15 days, and all victims within 2 months. Other organizations have similar requirements. WVI sends items to sustain up to 2,000 people for 7 days in the first phase. The second phase involves sending family survival kits, which can support up to 5,000 people for 30 days (Kovacs and Spens 2007).

One might argue that, instead of running the optimization once for a fixed time horizon, a rolling horizon approach would be more appropriate. However, organizations deal with dozens of disasters simultaneously and hundreds over years, so we are interested in aggregate decisions of where to put warehouses and pre-position supplies. These aggregate decisions do not change much with a rolling horizon, except perhaps if several mega-disasters coincide in the same region or when certain trends accelerate, e.g. global warming. Appendix A presents the algorithm we used to build our scenarios and provides an example to illustrate the process.

\subsection{Products and suppliers}

For each of the scenarios of our database, demand reflects the number of items that should be sent to affected regions within the various timeframes for each product, region, and time. It is assumed that demand for aid is limited to 8 essential products corresponding to the IFRC's recommendations of what it considers the most important resources for pre-positioning (See Table 1) 
Table 1: List of products (source IFRC: http://procurement.ifrc.org/catalogue)

\begin{tabular}{lllll}
\hline Description & $\begin{array}{l}\text { Purchase Cost } \\
(\mathrm{euro})\end{array}$ & $\begin{array}{l}\text { Weight } \\
(\mathrm{kg})\end{array}$ & $\begin{array}{l}\text { Volume } \\
\left(\mathrm{m}^{3}\right)\end{array}$ & $\begin{array}{l}\text { Packaging } \\
(\text { nb per pack) }\end{array}$ \\
\hline Wool blankets & 3 & 2 & 0,008 & 20 \\
Plastic sheeting & 109 & 55 & 0,18 & 40 \\
Interagency Emergency Health Kit & 7982 & 1133 & 5,85 & 10000 \\
Cholera Kits & 2084 & 1078 & 4,45 & 1200 \\
Mosquito nets & 4 & 4 & 0,0017 & 2 \\
Hygienic parcels & 3 & 0,44 & 0,01 & 5 \\
Kitchen Kits & 14 & 4,7 & 0,022 & 5 \\
Jerry cans (foldable) & 2 & 0,14 & 0,00042 & 2 \\
\hline
\end{tabular}

Suppliers for each item and their locations are known. No supplier can furnish all the products. For example, the United Kingdom has two kinds of suppliers. Global suppliers can provide plastic sheeting and jerry cans to any region, but no other products. Regular donors like the British Red Cross will supply any product to a crisis in Africa.

At this aggregate level we hypothesize that supplier stocks are unlimited and can meet any demands from any warehouse. Reality is less simple, but the risk of supplier inventory shortage is actually very low. Indeed, the availability of products is ensured by the number and diversity of available suppliers, the warehousing of contingency stocks, and written framework agreements with suppliers.

What can, and should, be considered is the location of future suppliers. Indeed, HOs choose to decentralize their logistics networks to facilitate building local capacities and strengthen developing economies. However, HOs differ in their opinions on this practice. Oxfam has built a strong network of local suppliers and sources close to $100 \%$ of its relief items in Africa, whereas WVI views local supply in Africa as limited, especially when compared to the much greater opportunities available in Asia. The potential for local supply therefore requires additional study to determine the impacts of changes in supply strategy on network design. The impact of supplier location on network design is discussed in section 5 . 


\section{An efficient facility location model for HOs}

Our model (see Appendix B) identifies the optimum number and location of warehouses on a regional scale. The world was divided into the 21 regions defined by the international disaster database EM-DAT. These regions constitute both the customers, or potential beneficiaries, and feasible warehouse locations. It did not make sense to optimize locations at the country level due to imprecise data on delivery costs and times and the obvious constraints of gathering a large amount of detailed data, as well as interpreting outputs from a huge MILP. We aimed to provide reliable results in contexts where decision-makers face enormous difficulties obtaining data, paying special attention to the relevance and realism of our inputs at a more aggregate level. We identified the comfort zones for which the existing network is suitable, and provided input to inform decisions on whether new warehouses should be added and existing ones relocated or closed.

The objective of the model is to minimize the sum of all costs, i.e. air and boat transportation costs from supplier to warehouse and from warehouse to beneficiaries, fixed costs of maintaining a functioning warehouse, and variable costs incurred by running the warehouse.

Constraints specify that the quantity of products delivered should equal demand, except when there is a stock-out. At $t=0$, a contingency stock is available in every open warehouse. This contingency stock is rebuilt after operations. In this study, a product cannot be delivered after the time horizon for the simple reason that, when operations are closed, logistic and relief teams leave the affected country and can no longer manage the shipments. We also added constraints to take into account the organization's existing network or limit the maximum number of warehouses to open. The MILP is a rather straightforward formulation which is why we do not provide a detailed description in the main text.

\section{Results and analysis}


Our aim is to give a taste of the richness of the results and insights from this study which is tailored to the IFRC's situation. Space limitations do not allow for a full description of all tests. For further details, see (Charles 2010). The main result is that a one-stage network, with regional warehouses, provides the most efficient response and is capable of satisfying demand. A two-stage network where the goods first pass through the first-stage regional warehouses, costs more than a centralized network. Decentralizing more by adding secondstage local warehouses at country levels is not justified. Regarding the number, size, and locations of warehouses, two analyses which did and did not take into account the actual IFRC network were performed.

\subsection{Optimal network without including actual warehouse locations}

Figure 3 presents a management summary of the research. First, we looked at which locations were considered optimal for our scenarios under different conditions (e.g., with or without local supply, with or without a limitation on the overall number of warehouses in the network). We then proposed various supply networks, choosing the number and location of warehouses based on all the outputs of the model. Finally, we validated the overall level of service of the proposed networks. We added the chosen design (imposing the locations and numbers of warehouses) as a constraint in the model and simulated the response to all the scenarios. The targeted level of service in figure 3 is the percentage of scenarios with no stock-outs, that is to say where the chosen supply network could respond to all demand on time. The number of warehouses needed depends on the number of operations to be managed simultaneously more than on the size of the disasters. The optimal number of warehouses in the network varies between 2 and 8. With only 2 warehouses, the targets regarding the quantities delivered and the time frames for deliveries cannot be met for one tenth of the operations. Having more than 4 warehouses is only efficient if fixed costs are reduced or if local supply is significantly available. 
Figure 3: Optimal number and location of warehouses depending on local agreements, local supply capacity and targeted level of service

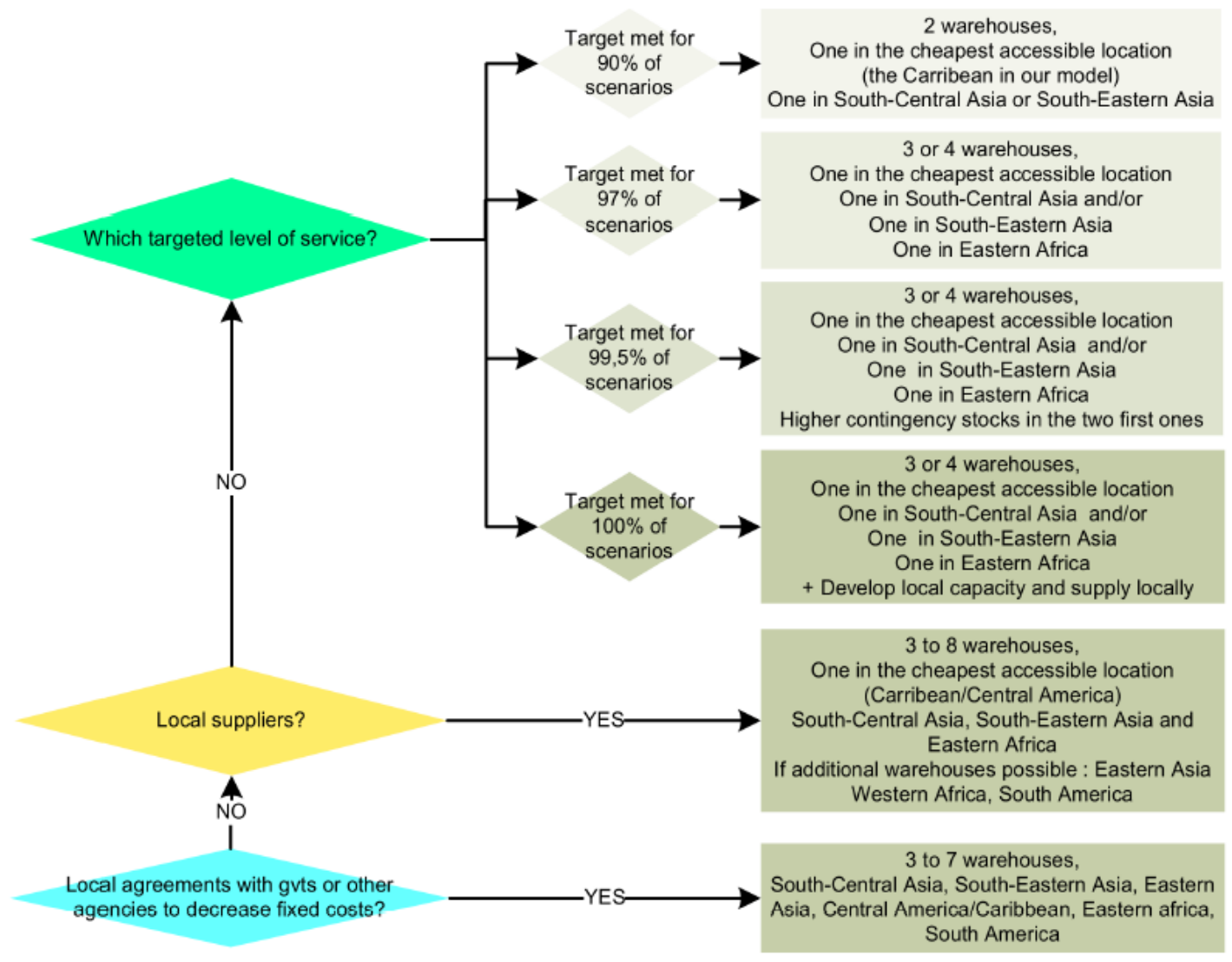

Figure 4: Summary of results regarding locations of warehouses

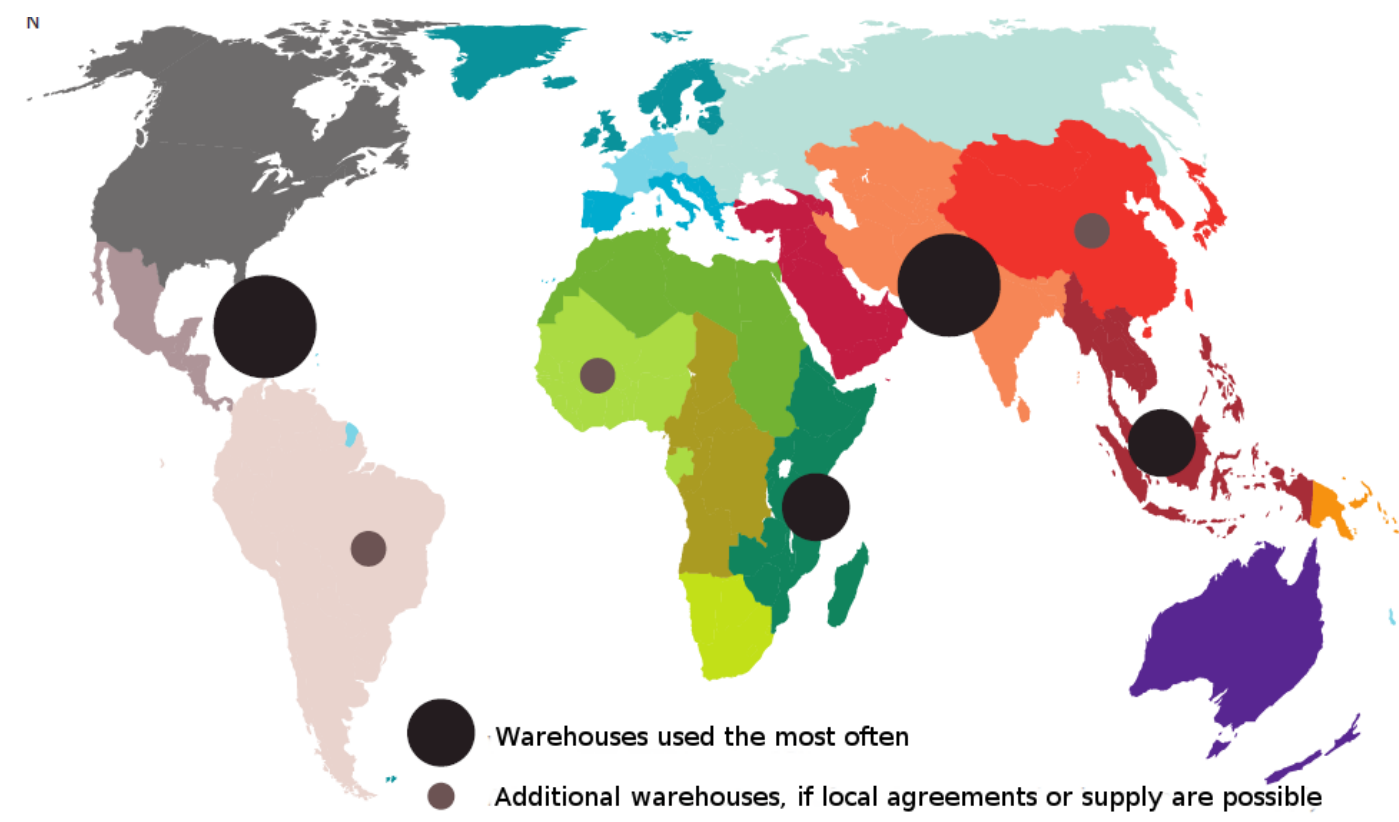


One central warehouse located where local agreements with governments or other NGOs decrease fixed costs is the most efficient option for small crises. This central warehouse will be used to complement local or regional warehouses when they cannot meet demand in case of large disasters. Given our dataset and the initial size of the contingency stock chosen by IFRC, this central warehouse should be positioned in the Caribbean or Central America. For medium-sized disasters, locations such as South Central Asia, South Eastern Asia, and Eastern Africa are recommended (see Figures 3 and 4). With higher contingency stocks, warehouses responding to medium or large-scale disasters can also handle smaller crises. The additional location in the Caribbean, therefore, is no longer necessary.

The use of local suppliers impacts both the efficiency and the effectiveness of the response, but not the locations selected by the MILP. The main difference is that with local suppliers more warehouses are used. One single global warehouse (in the Caribbean or Central America) is the preferred option only for small size disasters affecting less than 10,000 individuals. Our results show that for disasters affecting a larger population, if local supplies are available, a warehouse is located in the region in which the largest crisis occurs in $72 \%$ of our scenarios. Such warehouses need the support of a second warehouse in $16 \%$ of cases to complement the response when the size of the disaster requires it or to facilitate the management of simultaneous humanitarian operations occurring in other regions. The robustness of the warehouse locations to the use of local suppliers indicates that a logistics network built with global suppliers also remains optimal once the local network is developed. This point is extremely important because the capacity to supply locally is currently uncertain in many regions. It might exist but is difficult to assess without local resources, experience, or networks. HOs can choose locations first and then work on a supply strategy developing local capacity. 
Delivery capacities are also vital. Below $300 \mathrm{~m}^{3}$ per day, no matter how many warehouses, one cannot meet the targeted number of beneficiaries for at least $9 \%$ of the scenarios (see table 2).

Table 2: Impact of changes on warehouse delivery capacity

\begin{tabular}{|c|c|c|c|c|c|c|}
\hline \multirow{3}{*}{$\begin{array}{l}\text { Maximum number of products sent per day } \\
\text { Equivalence in } \mathrm{m}^{3}\end{array}$} & \multicolumn{3}{|c|}{$\begin{array}{l}\text { Optimal network per } \\
\text { scenario }\end{array}$} & \multicolumn{3}{|c|}{ Existing network (IFRC) } \\
\hline & 10000 & 100000 & Free & 100000 & 500000 & Free \\
\hline & $30 \mathrm{~m}^{3}$ & $300 \mathrm{~m}^{3}$ & & $300 \mathrm{~m}^{3}$ & $1500 \mathrm{~m}^{3}$ & \\
\hline Percentage of scenarios with stock-outs & $26 \%$ & $9 \%$ & $0 \%$ & $21 \%$ & $10,3 \%$ & $2 \%$ \\
\hline Mean number of warehouses used per scenario & 9 & 4 & 2 & 3 & 3 & 3 \\
\hline
\end{tabular}

\subsection{Optimization of an existing logistics network: application to the IFRC}

When the IFRC logistics department decentralized its supply network ten years ago, its first choice was to set up three regional logistics units (RLU) in Panama, Dubai, and Kuala Lumpur. We discuss changes to this configuration here.

To choose the location of one additional warehouse, we tested two options. One based on adding a warehouse in the location most frequently opened in our scenarios without imposing any constraint on location. The other considered the detailed performance of the suggested network. Indeed, the scenario approach highlights the performance gaps in the network and enables a clear understanding of which warehouse location is best for each type, size, and location of disaster. In the case of the IFRC, we considered the scenarios with stock-outs and checked our outputs to determine which location would offer the best response to these specific cases. Table 3 compares the costs and levels of service between networks with two to six warehouses. To complement the IFRC's three RLUs, the next optimal location remains South Central Asia, followed by East Africa. Scenarios in which the current IFRC network cannot meet expectations occur when it simultaneously manages more than six operations, with two or more in the same region. With respect to geographical location, the most difficult 
regions to reach on time are Melanesia and most of Africa's regions (West, East and Central Africa).

Table 3: Comparison of options to optimize IFRC's existing network. Total costs are out of pocket costs (stock-out costs not included) to respond to all natural crises within a year.

\begin{tabular}{|c|c|c|c|c|c|c|c|c|c|}
\hline & \multicolumn{3}{|c|}{ IFRC Network } & \multicolumn{4}{|c|}{ Modification of IFRC Network } & \multicolumn{2}{|c|}{ New Network } \\
\hline & $\begin{array}{l}\text { No } \\
\text { change }\end{array}$ & $\begin{array}{l}\text { Bigger } \\
\text { stocks }\end{array}$ & $\begin{array}{l}\text { Local } \\
\text { supply }\end{array}$ & $\begin{array}{l}\text { Plus } 1 \\
\text { W }\end{array}$ & $\begin{array}{l}\text { Minus } \\
1 \mathrm{~W}\end{array}$ & $\begin{array}{l}\text { Plus } \\
2 \mathrm{Ws}\end{array}$ & $\begin{array}{l}\text { Plus } \\
3 \mathrm{Ws}\end{array}$ & $\begin{array}{c}\text { Relocate } \\
\text { Ws }\end{array}$ & $\begin{array}{l}\text { Relocate } \\
+ \text { local } \\
\text { supply }\end{array}$ \\
\hline Western Asia & $\mathrm{X}$ & $\mathrm{X}$ & $\mathrm{X}$ & $\mathrm{X}$ & & $\mathrm{X}$ & $\mathrm{x}$ & & \\
\hline Central America & $\mathrm{X}$ & $\mathrm{X}$ & $\mathrm{X}$ & $\mathrm{X}$ & $X$ & $X$ & $\mathrm{x}$ & & \\
\hline South-Eastern Asia & $\mathrm{X}$ & $\mathrm{X}$ & $\mathrm{X}$ & $\mathrm{X}$ & $\mathrm{X}$ & $\mathrm{X}$ & $\mathrm{x}$ & & \\
\hline South Central Asia & & & & $\mathrm{X}$ & & $\mathrm{X}$ & $\mathrm{X}$ & $\mathrm{X}$ & $\mathrm{X}$ \\
\hline Eastern Africa & & & & & & $\mathrm{X}$ & $\mathrm{X}$ & $\mathrm{X}$ & $\mathrm{X}$ \\
\hline Caribbean & & & & & & & $\mathrm{X}$ & $\mathrm{X}$ & $\mathrm{X}$ \\
\hline Number of warehouses & 3 & 3 & 3 & 4 & 2 & 5 & 6 & 3 & 3 \\
\hline Total costs $(€)$ & 11,3E09 & $11,2 \mathrm{E} 09$ & $10,2 \mathrm{E} 09$ & 10,7E09 & $10,9 \mathrm{E} 09$ & $10,6 \mathrm{E} 09$ & $10,6 \mathrm{E} 09$ & $10,3 \mathrm{E} 09$ & $10,1 \mathrm{E} 09$ \\
\hline Possible savings (costs) & $0 \%$ & $0,9 \%$ & $9,7 \%$ & $5,3 \%$ & $3,5 \%$ & $6,2 \%$ & $6,2 \%$ & $8,7 \%$ & $10,6 \%$ \\
\hline $\begin{array}{l}\text { Percentage of scenarios } \\
\text { with stock-out }\end{array}$ & $3 \%$ & $0,5 \%$ & $0 \%$ & $3 \%$ & $9 \%$ & $2 \%$ & $1 \%$ & $3 \%$ & $3 \%$ \\
\hline $\begin{array}{l}\text { Total stock-out (nb } \\
\text { product late x nb days } \\
\text { waiting) }\end{array}$ & 878605 & 56808 & 0 & 168916 & 2319460 & 88926 & 56808 & 358620 & 98421 \\
\hline $\begin{array}{l}\text { Total costs, including } \\
\text { fictitious stock-out costs }\end{array}$ & $1,22 \mathrm{E} 10$ & 1,13E10 & $1,02 \mathrm{E} 10$ & $1,09 \mathrm{E} 10$ & $1,32 \mathrm{E} 10$ & $1,07 \mathrm{E} 10$ & 1,07E10 & $1,07 \mathrm{E} 10$ & $1,02 \mathrm{E} 10$ \\
\hline $\begin{array}{l}\text { Possible savings, stock- } \\
\text { out costs included }\end{array}$ & $0 \%$ & $7,6 \%$ & $16,25 \%$ & $10,75 \%$ & $-8,55 \%$ & $12,2 \%$ & $12,5 \%$ & $12,3 \%$ & $16,3 \%$ \\
\hline
\end{tabular}

Opening an additional warehouse in South Central Asia would be more effective globally in terms of both costs and service levels. Many disasters occur in this region, so transportation costs would decrease if resources were pre-positioned there given some global suppliers are in this region. Savings in transportation costs are higher than the increase in operating costs for opening this additional warehouse. Opening two additional warehouses in South Central Asia and East Africa would be an even better option. The location in East Africa is the best solution to reach the African regions difficult to access with only three RLUs. Adding additional warehouses increases global capacity only marginally. Instead of opening new warehouses, one could simply opt to increase existing contingency stocks. A higher contingency stock in the Caribbean or Central America and South Central Asia is recommended because these are regions where warehouses are opened most frequently in our 
scenarios. In terms of service levels, three large or six small warehouses are equivalent, but placing additional locations closer to the field is more cost effective.

If modifying the existing network is an option, closing the warehouse in Dubai would decrease costs by 3,5\% but highly impair the reactivity of the network (see Table 3). Relocating all the warehouses could produce better costs and service levels than the existing network. Although theoretically possible because of the small size of actual warehouses, relocation is not the best alternative when considering all consequences, from the loss of local networks with suppliers and other organizations, to the change management issues linked to relocating human resources.

Developing local supply capacity would decrease costs by $10,6 \%$ and enable delivering all the demand within the required timeframes, whatever the scenario. Without local supply a stockout would occur for five operations per year on average (see Table 3).

\section{Sensitivity Analysis}

Sensitivity analysis on various data and parameters was performed to validate the results. We analyzed the impact of variations in product type and location of suppliers, scenarios chosen (changes in crises type, frequency, and location), out of pocket costs (fixed, variable or transportation), stock-out costs, delivery times and level of service desired (reaching beneficiaries quicker or later for each timeframe, including the total length of operations; increasing the number of beneficiaries reached at the beginning of operations) (see (Charles 2010) for details). Here we report only sensitivity to changes in demand patterns, fixed costs and delivery times.

\subsection{Sensitivity to changes in demand patterns}

To validate the robustness of network design over time, we tested scenarios covering a longer period (557 scenarios built from past disasters over a period of 3 years). Between 2006 and 
2012, the locations of crises did not change significantly. The optimal locations chosen to respond to these crises were similarly stable. Figure 5 presents the locations of warehouses chosen with the IFRC's actual suppliers and no limit on the maximum number of warehouses allowed. The same stability over the years is observed in the results when using local suppliers and when limiting the number of warehouses.

Figure 5: Evolution of warehouse optimal locations

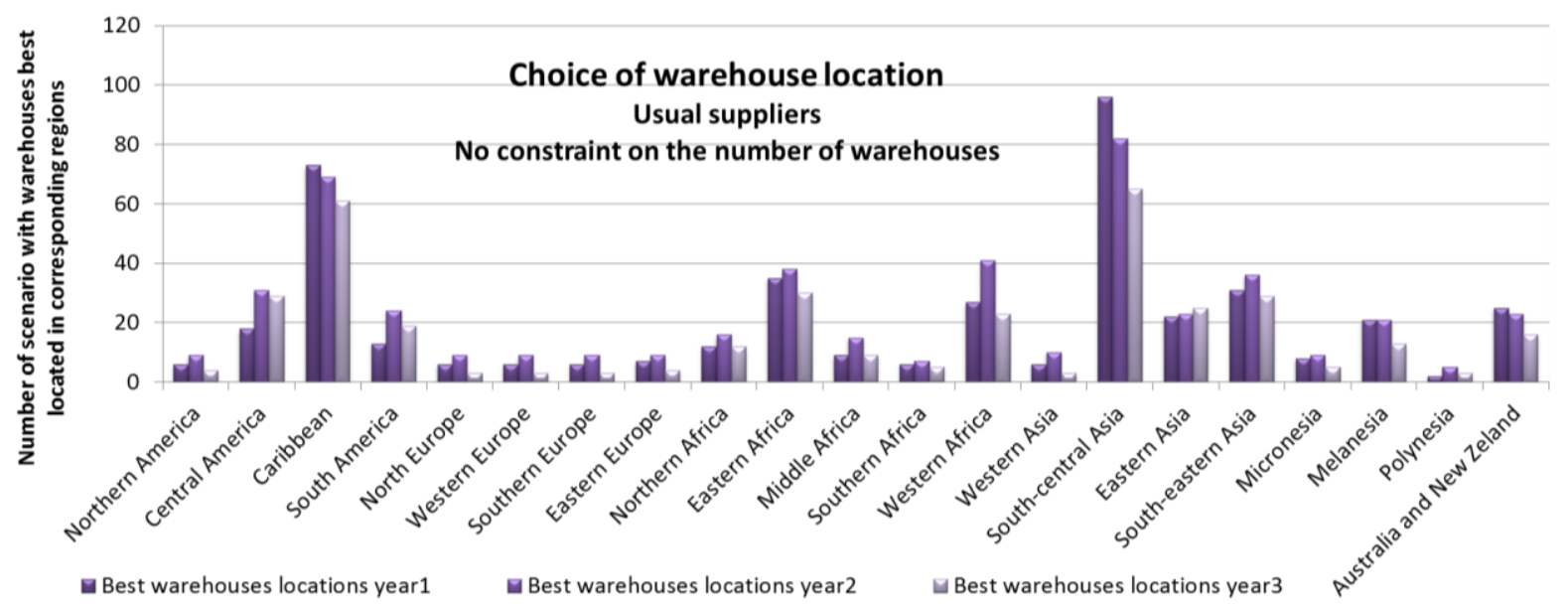

To assess sensitivity to changes in demand patterns, we analyzed future disaster trends such as the impact of climate change. We then built scenarios including these trends and analyzed their impact on location decisions. For example, our analysis showed an increase in small and medium-sized hydrological disasters in East Asia, South East Asia, and South Central Asia. If this trend continues, a warehouse in South Central Asia would certainly be recommended, taking advantage of its lower fixed and variable costs compared to other Asian locations. Delivery times and costs, and supplier locations also influence this result but to a lesser extent.

\subsection{Sensitivity to fixed costs}

Figure 6 shows variations caused by changes in fixed costs. As the map indicates, the geographical distribution of locations is more homogenous with lower fixed costs because 
more warehouses are opened in each scenario. Under high fixed costs the model centralizes the network to fewer, less expensive locations.

Figure 6: Sensitivity analysis on fixed costs

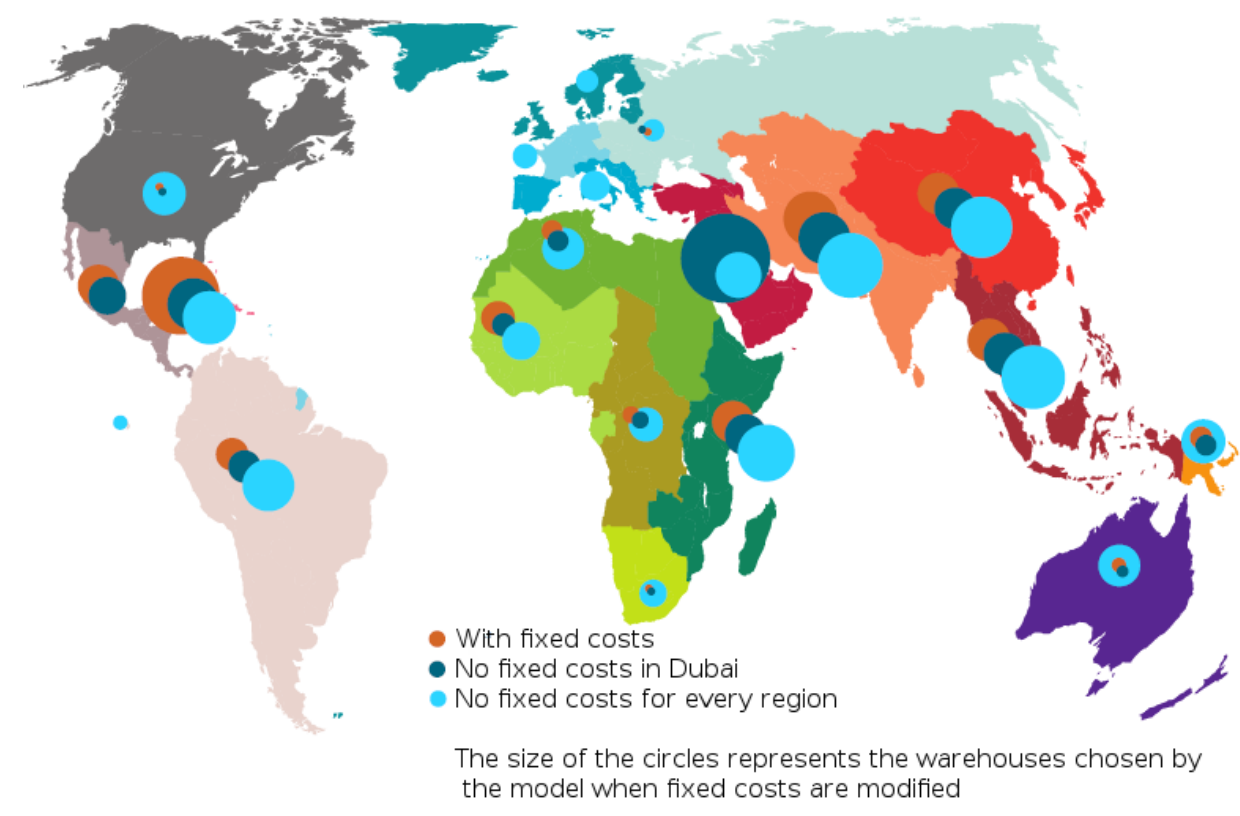

We also examined the impact of specific arrangements or conditions in host countries on the choice of warehouse locations. Western Asia is a good location for a warehouse only when taking into account their special agreements which attract HOs. Figure 6 clearly shows that, if the fixed costs associated with warehouse management can be reduced, then Dubai becomes a much better option than other regions. If however the standard of living and consequently the costs of maintaining a warehouse increase in the Caribbean, this region loses its attractiveness compared to both Central America and Western Africa.

\subsection{Sensitivity to delivery times}

Delivery times, especially from warehouse to beneficiaries or regions, might experience uncertainty after disasters strike. Our sensitivity analysis shows that longer delivery times result in more stock-outs, especially in the immediate aftermath of a disaster. Adding 2 days to delivery time from warehouses to beneficiaries increases stock-outs by $13 \%$ with an optimal network and by $75 \%$ with the IFRC current network. The model also chooses to open 
warehouses closer to operations when delivery times are longer which in turn increases costs because these locations are not always the cheapest (overall annual costs rise by $1.7 \%$ ).

A sensitivity analysis on the length of the response shows that operations taking more than 50 days have no impact on costs because 50 days already allow for transport by boat. Crises with stock-outs at 50 days also have stock-outs at 60 days because shortages typically occur at the start of operations. When closing operations earlier, there is no impact on service because 30 or even 20 days are enough to deliver products by air. Obviously costs are affected since more expensive modes of transport are required to reach the targeted populations faster.

\section{Conclusions}

This study has shown that optimization-based models and decision-support systems can provide rational answers to some questions: How do we ensure a swift, adequate response to disasters at the lowest possible cost? Where should we pre-position stock, and why? Which parameters impact the decision process?

Although the number of limitations and perspectives to consider in future research is high, the added value of this study is clear. The specifications of this work were written in close collaboration with HOs to take into account their specific needs and build a model reflecting their situation as accurately as possible, providing tailored recommendations for the IFRC. The approach is sufficiently general to allow HOs to use the methodology, but every organization must adapt the model to its mandate and mission and study for itself where to pre-position supplies. Obviously, an analysis by organization does not preclude information exchange or collaboration with other organizations.

We invested a lot of time and effort in analyzing the data on natural crises, many of which are recurrent from year to year. Our results show that the network designed to respond to these crises will remain optimal in the near future, with warehouses needed in South Central Asia 
and Central America. Most HOs have an operating supply network, so we took special care to take into account these facilities, proposing ways to improve an existing network. Our study differs from previous work which proposed theoretical solutions without much consideration of existing field realities. Our recommendations for the IFRC match its most recent changes to network design. It recently opened a regional logistics unit in Eastern Africa, one of the two locations we proposed to improve the network.

Our study is a prototype which can be improved in many ways. Additional discussions with other organizations to validate the results and their applicability are needed. We interviewed logisticians from large organizations, which might have some funding leeway as opposed to smaller organizations with strict budget constraints and therefore possibly other priorities. The target we set, to send assistance to all affected people within two months may not be realistic for small NGOs. Even for the IFRC, this target may evolve during the response process, depending on coordination opportunities or funding constraints.

Other ways of dealing with uncertainties could be compared or added to the model. The reliability of our results is closely related to the trustworthiness of our inputs, and especially the EM-DAT database. While this database has improved considerably, it can still be discussed, notably regarding time limitations set for disasters. For instance the Haiti earthquake in 2010 and the 2010 Cholera outbreak which was still ongoing in 2015 have only two data points in the database $(2010-2012)$. This introduces a bias, especially in case of slow onset disasters. In terms of robustness of our results over time we have analyzed network adaptations when climate change and its impact on crisis trends are taken into account, but we did not analyze population trends, especially in Africa, south and west Asia. Improvement in governance, country logistics performance, disaster preparedness, infrastructure, resilience programs, and education also impact the number of people affected by disasters, but we did not include those elements in this study. Local considerations, such as customs procedures, 
accessibility, and safety, could complement the present study to choose more precisely the location of warehouses within specific regions. The research presented in this paper included numerous analyses, many of which could not be included here for reasons of brevity. A full description is given in (Charles 2010).

\section{References}

Akkihal, A. R. (2006). Inventory Pre-positioning for Humanitarian Operations, Master Thesis, Massachusetts Institute of Technology (MIT).

Altay, N. and Green, L. V. (2006). “ORMS research in disaster operations management”. Eur J Oper Res 175.1, pp. 475-493.

Balcik, B. and Beamon, B. M. (2008). "Facility location in humanitarian relief". Int J Log Res Appl 11.2, p. 101.

Barbarosoglu, G., Ozdamar L., and Cevik, A. (2002). "An interactive approach for hierarchical analysis of helicopter logistics in disaster relief operations". Eur J Oper Res 140.1, pp. 118 -133. DOI: 10.1016/S0377-2217(01)00222-3.

Baud-Lavigne, B. (2012). Conception conjointe des nomenclatures et de la chaine logistique pour une famille de produits : outils d'optimisation et analyse, Phd Thesis, Université de Grenoble and Ecole Polytechnique de Montréal.

Bertsimas, D. and Thiele, A. (2006). "Robust and Data-Driven Optimization: Modern Decision Making Under Uncertainty". Models, Methods, and Applications for Innovative Decision Making. Chap. 5, pp. 95-122. DOI: 10.1287/educ.1063.0022.

Campbell, A. M. and Jones, P. C. (2011). "Prepositioning supplies in preparation for disasters". Eur J Oper Res 209.2, pp. 156-165. DOI: 10.1016/j.ejor.2010.08.029

Campbell, A. M., Vandenbussche, D. and Hermann, W. (2008). "Routing for Relief Efforts”. Transp Sci 42, pp. 127-145. DOI: 10.1287/trsc.1070.0209. 
Charles, A. (2010). Improving the design and management of agile supply chains: feedback and application in the context of humanitarian aid, $\mathrm{PhD}$ Thesis, Toulouse University - Mines Albi.

Charles, A., Lauras, M. and Van Wassenhove, L. N. (2010). "A model to define and assess the agility of supply chains: building on humanitarian experience" Int J Phys Distrib Log Manag 40.8/9, pp. 722-741. DOI: 10.1108/09600031011079355.

Duran, S., Gutierrez, M. A. and Keskinocak, P. (2011). "Pre-Positioning of Emergency Items for CARE International”. Interfaces 41, pp. 223-237. DOI: 10.1287/inte.1100.0526.

Guha-Sapir, D., Below, R., Hoyois Ph. - EM-DAT: The CRED/OFDA International Disaster Database - www.emdat.be - Université Catholique de Louvain - Brussels - Belgium.

Frigg, R. and Hartmann, S. (2012). "Models in Science". The Stanford Encyclopedia of Philosophy. Ed. by Edward N. Zalta.

Galindo, G. and Batta, R. (2013). "Review of recent developments in OR/MS research in disaster operations management”. Eur J Oper Res 230.2, pp. 201 -211. DOI: http://dx.doi.org/10.1016/j.ejor.2013.01.039.

Gatignon, A, Van Wassenhove, L. N., and Charles, A. (2010). "The Yogyakarta earthquake: Humanitarian relief through IFRC's decentralized supply chain”. Int J Prod Econ 126.1, pp. 102-110. DOI: 10.1016/j.ijpe.2010.01.003.

Gralla, E., Goentzel J., and Fine, C. (2014). “Assessing Trade-offs among Multiple Objectives for Humanitarian Aid Delivery Using Expert Preferences”. Prod Oper Manag 23.6, pp. 978989. DOI: $10.1111 /$ poms. 12110.

Hale, T. and Moberg, C. R. (2005). "Improving supply chain disaster preparedness: A decision process for secure site location”. Int J Phys Distrib Log Manag 35.3, pp. 195-207. DOI: $10.1108 / 09600030510594576$. 
Hoyois, P. Below, R., Scheuren, J-M., Guha-Sapir, D. (2007). Annual Disaster Statistical Review : The Numbers and Trends 2006. Centre for Research on the Epidemiology of Disasters (CRED).

IFRC (2007). Red Cross/Red Crescent Climate Guide. Climate Change: the Basics. Tech. rep. Klibi, W. Martel, A. and Guitouni, A. (2010). "The design of robust value-creating supply chain networks: A critical review". Eur J Oper Res 203.2, pp. 283-293. .

Kovacs, G. and Spens, K. M. (2007). "Humanitarian logistics in disaster relief operations". Int J Phys Distrib Log Manag 37.2, pp. $99-114$.

Lauras, M., Marques, G. and Gourc, D. (2010). “Towards a Multi-dimensional Project Performance Measurement System”. Decis. Support Syst. 48.2, pp. 342-353. DOI: 10.1016/j.dss.2009.09.002.

Lettieri, E., Masella, C., and Radaelli, G. (2009). "Disaster management: findings from a systematic review". Disaster Prev Manag Int J 18.2, pp. 117-136. DOI: 10 . 1108 / 09653560910953207.

Lodree, E. Jr and Taskin, S. (2007). “An insurance risk management framework for disaster relief and supply chain disruption inventory planning”. J Oper Res Soc 59.5, pp. 674-684. DOI: $10.1057 /$ palgrave.jors.2602377.

Mete, H. O. and Zabinsky, Z. B. (2010). "Stochastic optimization of medical supply location and distribution in disaster management". Int J Prod Econ 126.1, pp. 76-84. DOI: 10.1016/j.ijpe.2009.10.004.

Ozdamar, L., Ekinci, E. and Kucukyazici B. (2004). "Emergency Logistics Planning in Natural Disasters: Models and Algorithms for Planning and Scheduling Problems". Ann Oper Res 129, 217-245(29).

PAHO (2001). Humanitarian Supply Management and Logistics in the Health Sector. Pan American Health Organization. ISBN: 9275123756. 
Pedraza-Martinez, A. J. and Van Wassenhove, L. N. (2013). "Vehicle Replacement in the International Committee of the Red Cross". Prod Oper Manag 22.2, pp. 365-376. DOI: 10.1111/j.1937- 5956.2011.01316.x.

Peres, E. Q. and Brito, I. Jr (2012). "Humanitarian Logistics and Disaster Relief Research: Trends, Applications, and Future Research Directions". 4th International Conference on Information Systems, Logistics and Supply Chain. Quebec, Canada, p. 26-29.

Rawls, C. G. and Turnquist, M. A. (2010). "Pre-positioning of emergency supplies for disaster response". Transp Res Part B: Method. 44.4, pp. 521-534. DOI: 10.1016/j.trb.2009.08.003.

Salmeron, J. and Apte, A. (2010). "Stochastic Optimization for Natural Disaster Asset Prepositioning”. Prod Oper Manag 19.5, pp. 561-574. DOI: 10.1111/j.19375956.2009.01119.x.

Santoso, T., Ahmed, S., Goetscalckx, M., Shapiro, A. (2005). "A stochastic programming approach for supply chain network design under uncertainty". Eur J Oper Res 167.1, pp. 96 115. DOI: http://dx.doi.org/10.1016/j.ejor.2004.01.046.

Schmenner, R. W., Van Wassenhove, L. N., Ketokivi, M., Heyl, J. (2009). “Too much theory, not enough understanding”. $J$ Oper Manag 27.5, pp. 339-343. DOI: 10.1016/j.jom.2009.07.004.

Shapiro, A., Dentcheva, D. and Ruszczyski, A. (2009). Lectures on Stochastic Programming.. ISBN: 9780898716870.

Shapiro, J. F. (2000). Modeling the Supply Chain. 1st ed. South-Western College Pub. ISBN: 0534373631.

Simchi-Levi, D., Kaminsky, P. and Simchi-Levi, E. (2003). Designing and managing the supply chain. McGraw-Hill/Irwin. ISBN: 0072492562, 9780072492569. 
Simpson, N. C. and Hancock, P. G. (2009). "Fifty years of operational research and emergency response". J Oper Res Soc DOI: 10.1057/jors.2009.3.

Supply Chain Council (2006). Supply Chain Operations Reference Model 8.0. Tech. rep. URL: http://www.supply-chain.org/resources/scor/8.0.

Tzeng, G-H., Cheng, H-J.. and Huang, T. D. (2007). "Multi-objective optimal planning for designing relief delivery systems". Transp Res Part E: Log Transp Rev 43.6, pp. 673-686. DOI: 10.1016/j.tre.2006.10.012.

Ukkusuri, S. V. and Yushimito, W. F. (2008). "Location Routing Approach for the humanitarian Prepositioning Problem”. Transp Res Rec: J Transp Res Board 2089.1, pp. 1825. DOI: $10.3141 / 2089-03$.

Van Wassenhove, L. N. (2006). "Humanitarian aid logistics: supply chain management in high gear". J Oper Res Soc57, pp. 475-489.

Van Wassenhove, L. N. and Pedraza Martinez, A. J. (2012). "Using OR to adapt supply chain management best practices to humanitarian logistics". Int Trans Oper Res 19.1-2, pp. 307322. DOI: 10.1111/j.1475-3995.2010.00792.x.

Yi, W and Ozdamar, L. (2007). "A dynamic logistics coordination model for evacuation and support in disaster response activities". Eur J Oper Res 179.3, pp. 1177 -1193. DOI: http://dx.doi.org/10.1016/j.ejor.2005.03.077.

Yushimito, W. F., Jaller, M. and Ukkusuri, S. (2012). “A Voronoi-Based Heuristic Algorithm for Locating Distribution Centers in Disasters”. Netw Spa Econ 12.1, pp. 21-39. DOI: 10.1007/s11067- 010- 9140- 9. 


\section{Appendix A. How we built our scenarios}

For each of the scenarios of the data base, a demand Dpct is built to give, for each product $p$, region $c$ and time $t$, the number of items that should be sent to affected regions within the various time frames. The algorithm presented here explains how to build Dpct for crises starting at a given date $\mathrm{t} 0$. The demand is indicated for each day, starting at $t 0$ and finishing at $t 0+n b T$, where $n b T$ is the total duration of relief operations.

\footnotetext{
Algorithm 1: Construction of the demand per products, region and time to respond to all crisis starting at t0

Input:

- Disaster-List, a list of past disasters, detailing for each Crisis $i$ the starting date (TimeCrisis[i]), the type (TypeCrisis[i] = earthquake, flood, etc.), the region affected (Region[i]) and the total number of people affected (NbAff[i]).
}

- Needs[p] [CrisisType][c], which details which products $(p \in[0 . .7]$, from cholera kits to mosquito nets) are needed for each crisis type and region c. For example, Cholera kits are needed for an epidemic in Western Africa, but not for a Storm in Northern America.

Output: $\mathrm{D}[\mathrm{p}][\mathrm{c}][\mathrm{t}]$ which gives the cumulated number of each products $\mathrm{p}$ to send to regions $\mathrm{c}$ at times $t(t \in[t 0 . . t 0+50]$ in our study, which represents one and a half month of relief operations to respond to all crisis occurring at a given time t0)

initialisation : $\mathrm{nbAffTot}=0$; for each $\mathrm{p}, \mathrm{c}$ and time, $\mathrm{D}[\mathrm{p}][\mathrm{c}][$ time $]=0$;

foreach Crisis $i$ within Disaster-list do

\section{if TimeCrisis $[i]=t 0$ then}

Region $c=$ Region[i];

nbAffTot $=+=$ nbAff $[\mathrm{i}]$;

foreach Product $p$ do

if $N b A f f[i] \geq N b$ RescuedAtTime 2 then

foreach time $t \in[t 0+$ Time $1 . . t 0+$ Time2 $]$ do

$\lfloor\mathrm{D}[\mathrm{p}][\mathrm{c}][$ time $]=+=$ nbRescuedAtTimel $*$ Needs[p] [crisisType] [c];

foreach time $t \in[t 0+$ Time $2 . . t 0+T i m e 3]$ do

$\mathrm{D}[\mathrm{p}][\mathrm{c}][$ time $]=+=$ nbRescuedAtTime $2 *$ Needs[p] [crisisType] [c];

foreach time $t \in[t 0+$ Time $3 . . t 0+n b T]$ do

$\left\lfloor\mathrm{D}[\mathrm{p}][\mathrm{c}][\right.$ time $]=+=\operatorname{NbAff}[i]^{*}$ Needs[p] [crisisType] [c;;

else if $N b A f f[i] \geq N b R e s c u e d A t T i m e 1$ then

foreach time $t \in[t 0+$ Time1.. $t 0+$ Time 2$]$ do

$\left\lfloor\mathrm{D}[\mathrm{p}][\mathrm{c}][\mathrm{time}]=+=\right.$ nbRescuedAtTime ${ }^{*}$ Needs[p] [crisisType] [c];

foreach time $t \in[t 0+$ Time2.. $t 0+n b T]$ do

$\left\lfloor\mathrm{D}[\mathrm{p}][\mathrm{c}][\right.$ time $]=+=\operatorname{NbAff}[i]^{*}$ Needs $[\mathrm{p}][$ crisisType $][\mathrm{c}]$;

else

foreach time $t \in[t 0+$ Time1.. $t 0+n b T]$ do

$\mathrm{D}[\mathrm{p}][\mathrm{c}][$ time $]=+=\operatorname{NbAff}[i]^{*}$ Needs $[\mathrm{p}][$ crisisType $][\mathrm{c}]$; 
To further explain the construction of the demand matrix, consider kitchen kits designed to serve a family of 5 persons. If we follow IFRC specifications, the demand for kitchen kits $(p=7)$ after an earthquake in South Central Asia $(c=14)$ will be:

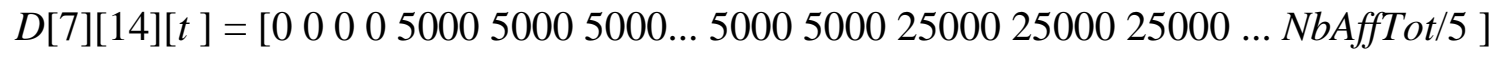

NbAffTot is the total number of people affected by the disaster, so NbAffTot/5 products are needed by the end of operations. The consolidated matrix of demand is then used as input to the MILP to identify the best warehouse locations.

\section{Appendix B. Model and notations}

\begin{tabular}{|c|c|c|}
\hline Notation & Nature & Definition \\
\hline \multicolumn{3}{|l|}{ Indices } \\
\hline$p$ & $p \in[0 . .7]$ & Product \\
\hline$s$ & $S \in[0 . .28]$ & Supplier \\
\hline$w$ & $w \in[0 . .20]$ & Warehouse \\
\hline$c$ & $c \in[0 . .20]$ & "Customer" or beneficiaries, i.e. affected region \\
\hline$t \quad t$ & $t \in[0 . . \mathrm{nbT}]$ & Time ( $n b T$ is the duration of operations) \\
\hline \multicolumn{3}{|c|}{ Variables } \\
\hline$Q B D_{p w c t}$ & Float & $\begin{array}{l}\text { Quantity of products } p \text { delivered from warehouse } w \text { to the affected region } c \text { by boat } \\
\text { at time } t\end{array}$ \\
\hline$Q B U_{p s w t}$ & Float & Quantity of products $p$ delivered from supplier $s$ to warehouse $w$ by boat at time $t$ \\
\hline$Q F_{p c t}$ & Float & Quantity of products $p$ delivered to the region $c$ at time $t$ \\
\hline$Q P_{p w t}$ & Float & Quantity in stock of products $p$ in warehouse $w$ at time $t$ \\
\hline$Q P D_{p w c t}$ & Float & $\begin{array}{l}\text { Quantity of products } p \text { delivered at time } t \text { to the affected region c from warehouse } \\
w \text { by plane }\end{array}$ \\
\hline$Q P U_{p s w t}$ & Float & Quantity of products $p$ delivered from supplier $s$ to warehouse $w$ by plane at time $t$ \\
\hline Stockout $_{p c t}$ & Float & Quantity of products $p$ which were not delivered to beneficiaries $c$ at time $t$ \\
\hline$W C h_{w}$ & Boolean & $W C h w=1$ if the warehouse $w$ should be opened ;WChw $=0$ otherwise \\
\hline \multicolumn{3}{|r|}{ 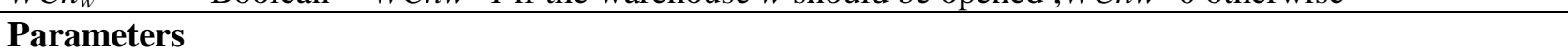 } \\
\hline coef & Float & $\begin{array}{l}\text { Coefficient to enable the modification of contingency stock, to visualize its impact } \\
\text { on outputs }\end{array}$ \\
\hline $\operatorname{Cost}_{w}$ & Float & Fixed costs to run the warehouse \\
\hline $\operatorname{Cost} V_{w}$ & Float & Variable costs to run the warehouse \\
\hline$D_{p c t}$ & Float & Demand of each product at the affected region $c$ at time $t$ \\
\hline$D C B D_{p w c}$ & Float & $\begin{array}{l}\text { Delivery cost by boat to deliver product } p \text { from potential warehouse } w \text { to affected } \\
\text { region } c \text { (Downstream potential warehouse) }\end{array}$ \\
\hline$D C B U_{p s w}$ & Float & $\begin{array}{l}\text { Delivery cost by plane to deliver product } p \text { from supplier s to potential warehouse } \\
w \text { (Upstream potential warehouse) }\end{array}$ \\
\hline$D C P D_{p w c}$ & Float & $\begin{array}{l}\text { Delivery cost by plane to deliver product } p \text { from potential warehouse } w \text { to affected } \\
\text { region } c \text { (Downstream potential warehouse) }\end{array}$ \\
\hline$D C P U_{p s w}$ & Float & $\begin{array}{l}\text { Delivery cost by plane to deliver product } p \text { from supplier s to potential warehouse } \\
w \text { (Upstream potential warehouse) }\end{array}$ \\
\hline $\operatorname{dim}_{p}$ & Float & $\begin{array}{l}\text { Number of affected people able to use the product. Its presence is mandatory to } \\
\text { take into account the packaging of products (a kitchen set is designed for } 5 \text { persons } \\
\text { for example) }\end{array}$ \\
\hline
\end{tabular}




\begin{tabular}{|c|c|c|}
\hline$D T B D_{w c}$ & Float & $\begin{array}{l}\text { Delivery time by boat to deliver a product from potential warehouse } w \text { to affected } \\
\text { region } c \text { (Downstream potential warehouse) }\end{array}$ \\
\hline$D T B U_{s w}$ & Float & $\begin{array}{l}\text { Delivery time by boat to deliver a product from supplier } s \text { to potential warehouse } \\
w \text { (Upstream potential warehouse) }\end{array}$ \\
\hline$D T P D_{w c}$ & Float & $\begin{array}{l}\text { Delivery time by plane to deliver a product from potential warehouse } w \text { to affected } \\
\text { region } c \text { (Downstream potential warehouse) }\end{array}$ \\
\hline$D T P U_{s w}$ & Float & $\begin{array}{l}\text { Delivery time by plane to deliver a product from supplier } s \text { to potential warehouse } \\
w \text { (Upstream potential warehouse) }\end{array}$ \\
\hline$M$ & Float & $\begin{array}{l}\text { Initially used in constraint (8) without physical signification. Can also be used to } \\
\text { limit the warehouse size, i.e. maximum number of products which can be in a } \\
\text { warehouse in the same day }\end{array}$ \\
\hline nbAffTot & Integer & Total number of Affected people \\
\hline$n b T$ & Integer & Duration of operations \\
\hline$Q S p_{w}$ & Float & $\begin{array}{l}\text { IFRC Contingency stocks. Corresponds to a quantity of products } p \text { to keep in stock } \\
\text { at warehouse } w \text { prior to disasters in order to enable an immediate response (5days) }\end{array}$ \\
\hline$S$ & Float & Penalty costs, per day and per product not delivered on time \\
\hline
\end{tabular}

The objective of the model is to minimize the sum of all costs:

$$
\begin{gathered}
\operatorname{Min} \sum_{p} \sum_{s} \sum_{w}\left(D C P U_{p s w} \times \sum_{t} Q P U_{p s w t}\right)+\sum_{p} \sum_{s} \sum_{w}\left(D C P D_{p w c} \times \sum_{t} Q P D_{p w c t}\right) \\
+\sum_{p} \sum_{s} \sum_{w}\left(D C B U_{p s w} \times \sum_{t} Q B U_{p s w t}\right)+\sum_{p} \sum_{s} \sum_{w}\left(D C B D_{p w c} \times \sum_{t} Q B D_{p w c t}\right) \\
+\sum_{w}\left(\operatorname{Cost}_{w} \times W C h_{w}\right)+\sum_{t} \sum_{w} \operatorname{Cost}_{w} \times\left(\sum_{p} \sum_{s}\left(Q P U_{p s w t}+Q B U_{p s w t}\right)+\sum_{p} \sum_{c}\left(Q P D_{p w c t}+Q B D_{p w c t}\right)\right) \\
+\sum_{p} \sum_{w} \sum_{c} \sum_{t}\left(\text { Stockout }_{p c t} \times \operatorname{dim}_{p} \times S\right)
\end{gathered}
$$

The terms represent air and boat transportation costs, from supplier to warehouse and from warehouse to beneficiaries, fixed costs of maintaining a functioning warehouse, and variable costs incurred by running the warehouse, depending on the number of products handled and employees required, and penalty costs incurred if products are late.

Constraints are as follows:

$$
\begin{array}{lll}
\forall p, c, t=0 & Q F_{p c 0}=\sum_{w} Q P D_{p w c 0}+Q B D_{p w c 0} & Q F_{p c t}=0 \\
\forall p, c, t \geq 1 & Q F_{p c t}=Q F_{p c(t-1)}+\sum_{w} Q P D_{p w c t}+\sum_{w} Q B D_{p w c t} & Q F_{p c t} \geq 0 \\
\forall p, c, t & Q F_{p c t} \geq D_{p c t}-\text { Stockout }_{p c t} & \\
\forall w & \sum_{p} \sum_{c} \sum_{t}\left(Q P D_{p w c t}+Q B D_{p w c t}\right) \leq M \times n b A f f T o t \times W C h_{w}
\end{array}
$$




$$
\begin{aligned}
& \forall p, w, t=0 \quad Q P_{p w 0}=Q S_{p w} \times W C h_{w} \\
& \forall p, w, t \geq 1 \quad Q P_{p w t}=Q P_{p w(t-1)}+\sum_{s} Q P U_{p s w t\left(i f t>D T P U_{s w}\right)} \\
& +\sum_{s} Q B U_{p s w t\left(i f t>D T B U_{s w}\right)} \\
& -\sum_{c}^{s} Q P D_{p w c\left(t+D T P D_{p w c}\right)}-\sum_{c} Q B D_{p w c\left(t+D T B D_{p w c}\right)} \\
& \forall p, w \quad Q P_{p w n b T}=Q S_{p w} \times W C h_{w} \\
& \forall p, s, w, t \leq D T P U_{s w} \quad Q P U_{p s w t}=0 \quad \forall p, s, w, t \leq D T B U_{s w} Q B U_{p s w t}=0 \\
& \forall p, w, c, t \leq D T P D_{w c} \quad Q P D_{p w c t}=0 \quad \forall p, s, w, t \leq D T P D_{w c} Q P D_{p w c t}=0 \\
& W C h_{2}=1 \quad W C h_{15}=1 \quad W C h_{19}=1 \\
& \sum_{w} W C h_{w} \leq 4
\end{aligned}
$$

Constraints (5) and (6) define the cumulated quantities of products delivered to the affected regions. At the end of operations, the quantity of products delivered should equal demand (7), unless there were stock-outs. Stock-out is the quantity of products $p$ not delivered to beneficiaries $c$ at time $t$ while there is demand. If a product is five days late the cost of these five days is added to the total cost, even if the product arrived before the end of operations. If the product did not arrive at all, then (nbT-expected delivery time) times the cost of stock-out for this product is added to the costs. Constraint (8) imposes that products go only through open warehouses. If the chosen value for $M$ is too low, it acts as a constraint on the size of the warehouse. Constraint (9) represents the inventory balance. At $t=0$, contingency stock $Q S_{p w}$ is maintained in every open warehouse. This contingency stock is rebuilt after operations (10). A product cannot be delivered after $n b T$ since when operations are closed logistics and relief teams are gone. Constraints (11) and (12) ensure no product can arrive before the delivery lead time. Term (13) enables to include the organization's existing network. For example, IFRC has three regional warehouses already opened, in Panama $(c=2)$, Kuala Lumpur $(c=15)$ and Dubai $(c=19)$. Constraint (14) puts a limit on the number of warehouses (4 in this example). 